American Journal of Applied Sciences 5 (9): 1127-1134, 2008

ISSN 1546-9239

(C) 2008 Science Publications

\title{
Predictors of Technology Deployment Among Malaysian Teachers
}

\author{
Naresh Kumar, Raduan Che Rose and Jeffrey Lawrence D'Silva \\ Graduate School of Management, Universiti Putra, Malaysia
}

\begin{abstract}
Technologies advocate researchers had identified a number of factors that affect individual teachers' usage of computers. Nevertheless mix results were reported in literature. Hence, this study used personal characteristics and the technology acceptance constructs to understand the Actual Usage of Computer (AUC) among Malaysian teachers. The final model derived from this study was able to explain and predict approximately $54.5 \%$ of the variance in AUC. There were five variables significantly predicts the AUC and the strongest among them is perceived ease-of-use, followed by perceived usefulness, job relevance, computer compatibility and attitude. It is believed that the findings of this study would add new perspective on understanding the complexities associated with computer and learning among teachers.
\end{abstract}

Key words: Technology, Teachers, Malaysia

\section{INTRODUCTION}

Information Technology (IT) is an important element to open up huge potential for increased efficiency through the internet, e-commerce and the instantaneous delivery of information anywhere in the world and at any time ${ }^{[1]}$. Acknowledging the impressive developments in the information technology, Malaysia has implemented the Multimedia Super Corridor (MSC) Project to boost IT to the forefront and as one of the steps to transform the nation from an industrial economy to a knowledge-based one. On top of it, huge budget had been allocated for Information and Communication Technology (ICT) related programmes and projects so as to achieve a wider diffusion of IT knowledge among the people in the country ${ }^{[2]}$. For example in the 2005 Budget, RM16.3 billion has been allocated to the Ministry of Education to create a knowledge-society ${ }^{[3]}$ and to intensify the usage of information and communication technology in schools. As these examples suggest, policy makers appear convinced that computer technology is essential if students are to be prepared to face the challenges of the borderless world.

A revolutionizing transition like this would require a fundamental shift among the people whereby it would lean towards creating a more technologically literate workforce that is capable to face challenges of a global economy and a work environment that is characterized by intensive usage of technology and innovation. Over the past decades, the roles of IT in modern education have also increased significantly ${ }^{[4]}$. To achieve this transition, the school education system is required to face a revamp, so that it would prepare students for challenges in a knowledge-centric economy. Moreover, in order to carry out their new roles effectively, teachers need to have the capabilities and skills to use technology and be prepared to adopt and use computers to enhance teaching and learning for students and the subject area they will teach. In Malaysia, the Mathematics, Science and English language (MSE) teachers were given extensive training since 2002 by the Ministry of Education besides placing these teachers under a healthier incentive scheme. Nevertheless, the usage of ICT equipment in the process of teaching and learning has been dawdling over the years ${ }^{[5]}$. On average the MSE teachers in Malaysian schools only used ICT equipment for about $29 \mathrm{~h}$ in the two year period which is considered to be very stumpy ${ }^{[6]}$.

There is extensive research in computer education that provides evidence on the gender differences in computer technology adoption and usage ${ }^{[7]}$. Wong et al. ${ }^{[8]}$, Houtz and Gupta ${ }^{[9]}$ and Lee ${ }^{[10]}$ found that male teachers were more confident and had a greater usage of computers compared to their female counterparts. Besides that, age and training in computer usage also have an affect on teachers' AUC. In general, prior research has suggested that younger teachers have a greater tendency to use computers compared to their older and more experienced colleagues ${ }^{[11,12,13]}$. In relation to computer training, numerous research have shown that one who attends more training believed in

Corresponding Author: Dr. Naresh Kumar, Graduate School of Management, Universiti Putra, Malaysia,

Fax: +60-603-8943-4019 
the benefits of computer technology and are more ready to it in classroom ${ }^{[14,8,15,16]}$.

Moreover, teaching experience and main subjects taught also had an influence on teachers AUC. Research indicates that teachers with less teaching experience and are just beginning their teaching career will be more concerned with learning technology at a faster pace to be proficient in their career and thus adopt and use computer into their instruction by whatever means are available ${ }^{[17]}$. Besides, it was also identified in previous research that subjects taught in schools as one of the factors that serve to influence the usage of computers in schools ${ }^{[18]}$ whereby science and technology teachers tend to use the computers more in classrooms compared with other subjects.

Considerable research has been carried out that predict technology acceptance constructs that influence the AUC among individuals ${ }^{[4]}$. Previous research on the use of computers has found empirical support for attitude as driver of $\mathrm{AUC}^{[19]}$. It was identified that teachers' positive attitudes towards computers are pertinent for effective usage of computers in schools. Moreover in-line with reasoning applied in the Theory of Reasoned Action (TRA) and Technology Acceptance Model (TAM), it could be hypothesized that there exists a direct and positive effect between attitude and AUC.

Perceived usefulness as described by Hu et al ${ }^{[4]}$ is the extent to which computer is considered by an individual to be useful, whereas perceived ease of use is the degree to which an individual views his or her use of computer to be free of effort. Venkatesh and Morris $^{[20]}$, Davis ${ }^{[21]}$ and Hu et al. ${ }^{[4]}$ had avowed the importance of perceived usefulness and perceived ease of use and its significant positive influence on AUC. Continuing research efforts on computer self-efficacy can be observed in recent studies ${ }^{[22]}$, which confirm the critical role that computer self-efficacy plays in understanding individual response to computer technology. There exists a link between computer selfefficacy and AUC. Based on Hu et al. ${ }^{[4]}$ model and Theory of Planned Behavior (TPB), it was found that computer self-efficacy had a significant positive influence on AUC.

Job relevance is defined as to the extent to which a teacher considers computer to be relevant to his or her job. Past research has depicted the positive effect of job relevance on $\mathrm{AUC}^{[23,24]}$. Research also indicated positive influence of subjective norms on teachers' AUC $^{[25,26]}$. Numerous studies have shown that teachers' readiness to use technology will increase as a result of strong support systems that include colleagues, administrators, parents and other members in the community ${ }^{[27]}$.

Based on Hu et al..$^{[4]}$ model, it was identified that both job relevance and subjective norm had a significant positive influence on AUC. Over the past decade there had been research that examined the effect of computer compatibility on AUC. Computer compatibility is defined as teacher's acceptance of computer being well-suited with their working life styles and consistent with their existing values and able to satisfy their personal needs ${ }^{[4]}$. Morton ${ }^{[28]}$ and Dusick $^{[29]}$ study provide evidence of the significant effect of computer compatibility on AUC. The study showed that teachers enhance their usage of computers since they found they are compatible with it. Hu et al. ${ }^{[4]}$ model also identified that hardware and software compatibility positively influences teachers AUC.

This study used the technology acceptance model as its primary theoretical understanding on the usage of computer among MSE teachers. The technology acceptance model is a well-known model for predicting and explaining individual behavior on the usage of information technology $y^{[30]}$. However, to the researchers' knowledge after a thorough search on all the available databases and local and foreign journals, no studies pertaining to computer usage among MSE school teachers had been carried out in Malaysia using the extended technology acceptance model as the foundation for theoretical framework. Hence, this study aims to explore to what extent the socio-demographic factors and technology acceptance constructs jointly predicts the AUC among MSE secondary school teachers. It is hoped that this study would contribute to the existing literature by examining different variables that might have been neglected previously. Consequently, this would add to the body of knowledge pertaining to AUC among school teachers.

\section{MATERIALS AND METHODS}

The primary data was obtained through a survey using self-administered questionnaire. The instrument used in this study consisted of three parts. The first part seeks information on the respondents' sociodemographic profiles: gender, age, teaching experience, main subject taught using computer and training in computer usage. The second part of the instrument measures the AUC of the respondents. Questionnaire developed by Kellenberger and Hendricks ${ }^{[31]}$ (2000) was adapted to measure the AUC. The total number of items to measure AUC were forty three and all these items consisted statements, which required the respondents to state the degree that ranges from never 
to always on their weekly usage of computer for the subsections of (a) in preparation for/actual teaching and learning, (b) administration and (c) personal needs. Likert scale with continuum of 1-5 was used. The third part of the instrument measured the technology acceptance constructs. There were seven dimensions that accommodate the technology acceptance construct: attitude, computer self-efficacy, perceived usefulness, perceived ease of use, computer compatibility, job relevance and subjective norm. The items in the technology acceptance constructs were adapted from prior studies using the technology acceptance model applications, many which have already established their reliability and validity ${ }^{[4,32,30,33,34,21]}$.

Each dimension in the technology acceptance constructs has a different number of items. The total number of items was 86 and the instrument has been constructed in a way where each item required the respondent to determine the degree on the use of computer and by using the computer. Each statement of the instrument was measured on a common Likert scale, continuum of 1-5 with 1 representing strongly disagrees and 5 representing strongly agree. From the analysis, it was identified that the Cronbach alpha of all constructs were between 0.80-0.92, exceeding Nunnally's ${ }^{[35]}$ recommended threshold of 0.7 . Thus, the instrument used in this study showed a good level in terms of reliability.

The target population was the MSE secondary school teachers in the state of Selangor. However, the accessible population in this study was the MSE secondary school teachers covering 65 secondary schools in the district of Petaling, Selangor. Based on the figures provided by the Selangor State Education Department, the total number of MSE secondary school teachers in the district of Petaling is 3,432, that is, there are 1,108 Mathematics teachers $(32 \%$ of the total population), 1,451 Science teachers ( $42 \%$ of the total population) and 873 English language teachers (26\% of the total population).

The required sample size to fulfill the purpose of the study was deemed as $358(\mathrm{~N}=3,432)$ base on the formula derived from Yamane ${ }^{[36]}$. Stratified sampling was used to selection MSE teachers from the 65 secondary schools. The principals were given the discretion to distribute the questionnaires to the teachers concerned. Each school was given the maximum of three weeks to return the completed questionnaires. Out of the 358 distributed questionnaires, 318 were returned and usable. The stepwise multiple regression analysis using SPSS was performed to determine the significant contributors among the predictor variables in explaining AUC.

\section{DISCUSSION}

Looking at the distribution of gender of the respondents, it revealed that out of the 318 respondents, $75 \%$ were female teachers compared to only $25 \%$ of male teachers. The age of the respondents range from 21-50 with the highest age group being in the range of $31-40(43 \%)$, followed by the range of $41-50(42 \%)$ and the last group is the one that is between the ranges of 21-30 (15\%). The distribution of teaching experience was that there were 102 with 16-20 years, 98 with 11 15 years, 70 with 6-10 years and 48 with $1-5$ years. The distribution of main subjects taught was that there were 140 teachers who teach Science, 107 who teach Mathematics and 71 teachers who teach English language. Meanwhile, in terms of the distribution of training in computer usage was that there were 231 teachers who have moderate level of exposure, 59 teachers having high level of exposure and 28 teachers with low level of exposure.

The objective of this study is to identify the best model to explain AUC among MSE secondary school teachers. Hence, multiple regression statistical procedure was performed. The results of the multiple regression on the significant contributors of AUC would greatly help in recognizing specific insights of AUC among MSE teachers and eventually able to derive more appropriate recommendations to enhance the AUC among MSE secondary school teachers in Malaysia.

Three multiple regression analysis using the stepwise method was carried out to identify the best-fit model that would explain AUC among MSE secondary school teachers. The first multiple regression model was on the components of technology acceptance constructs with AUC, followed by the second model of socio-demographic factors with AUC and eventually the third model was the combination of technology acceptance constructs and socio-demographic constructs with AUC. The outcome of the multiple regression analysis is shown in Table 1, 2 and 3.

The significant contributors of the first model that consisted of the components of the technology acceptance constructs towards AUC as shown in Table 1 revealed that the value of adjusted $R^{2}$ was .468 and there were five constructs that showed significant predictors of AUC. The strongest predictor was perceived ease of use $(\beta=0.419)$, followed by perceived usefulness $(\beta=0.309)$, job relevance $(\beta=0.223)$, computer compatibility $(\beta=0.195)$ and attitude $(\beta=0.168)$. Table 2 showed the significant contributors of socio demographic factors towards AUC. 
Am. J. Applied Sci., 5 (9): 1127-1134, 2008

Table 1: Technology acceptance constructs as predictors of AUC

\begin{tabular}{lllll}
\hline Variable & Unstandardized coefficients (B) & Standardized coefficients $(\beta)$ & t-value & p-value \\
\hline Perceived ease of use & 0.357 & 0.419 & 9.806 & 0.0001 \\
Perceived usefulness & 0.302 & 0.309 & 7.105 & 0.0001 \\
Job relevance & 0.247 & 0.223 & 5.167 & 0.0001 \\
Attitude & 0.141 & 0.168 & 4.285 & 0.0001 \\
Computer compatibility & 0.217 & 0.195 & 4.599 & 0.0001 \\
\hline Note: Model statistics: $\mathrm{R}=0.686, \mathrm{R}^{2}=0.471$, Adj. $\mathrm{R}^{2}=0.468, \mathrm{~F}=61.72, \mathrm{p}=0.0001$ and $\mathrm{df}=5$ & &
\end{tabular}

Table 2: Socio demographic factors as predictors of AUC

\begin{tabular}{|c|c|c|c|c|}
\hline Variable & Unstandardized coefficients (B) & Standardized coefficients $(\beta)$ & t-value & p-value \\
\hline Main subject taught & 0.108 & 0.213 & 3.219 & 0.0001 \\
\hline Training in computer usage & 0.109 & 0.232 & 3.935 & 0.0001 \\
\hline \multicolumn{5}{|c|}{ Note: Model statistics: $\mathrm{R}=0.365, \mathrm{R}^{2}=0.133$, Adj. $\mathrm{R}^{2}=0.125, \mathrm{~F}=16.08, \mathrm{p}=0.0001$ and $\mathrm{df}=2$} \\
\hline \multicolumn{5}{|c|}{ Table 3: The best model for AUC } \\
\hline Varlable & Unstandardized coefficients (B) & Standardızed coefficients ( $\beta$ ) & t-value & p-value \\
\hline Perceived ease of use & 0.365 & 0.429 & 10.415 & 0.0001 \\
\hline Perceived usefulness & 0.284 & 0.291 & 06.934 & 0.0001 \\
\hline Job relevance & 0.212 & 0.191 & 04.544 & 0.0001 \\
\hline Attitude & 0.139 & 0.116 & 03.007 & 0.0001 \\
\hline Computer compatibility & 0.125 & 0.149 & 10.415 & 0.0001 \\
\hline
\end{tabular}

Compared to the first model of the components of technology acceptance constructs, the value of adjusted $\mathrm{R}^{2}(0.133)$ obtained for the significant contributors of socio demographic factors was lower. Both training in computer usage $(\beta=0.232)$ and main subjects taught $(\beta=0.213)$ were the significant contributors towards AUC in this second model. All the technology acceptance constructs and socio demographic factors were placed into a single simultaneous multiple regression to determine the predictor to aid the development of the third best model for AUC, using SPSS procedure for ordinary least square regression, ANOVA with the maximum $\mathrm{R}^{2}$ option.

This step revealed that five variable model being the best model for AUC. The model showed that perceived ease of use, perceived usefulness, job relevance, computer compatibility and attitude was the best predictors for AUC among MSE secondary school teachers with the best model $R^{2}=0.553$. The multiple $R$ obtained in this model was 0.743 and this exhibits a significant high correlation between the observed value and the predicted value of the criterion variable. The significant F-value is evidence that the model fit the data. Thus it was concluded that there is a linear relationship between the predictors and the AUC. The adjusted $\mathrm{R}^{2}$ was 0.545 , which means that the selected variables were able to explain $54.5 \%$ of the variation in the AUC among MSE secondary school teachers. The third model recorded the highest adjusted $\mathrm{R}^{2}$. Thus, this was the best-fit model to explain the AUC for this study. Table 3 shows the results of this analysis.

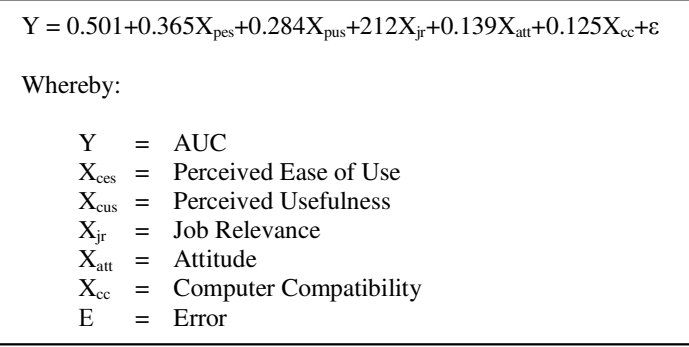

Fig. 1: Perceived AUC model

The variance inflation factor (VIF) values were used to assess collinearity or multicollinearity among the independent variables. All the VIF values were between 1.312 and 2.553 that are below the commonly accepted threshold value of $10.00^{[37]}$. Thus, it was concluded that there were no collinearity or multicollinearity problem among the predictor variables. Based on the Table 3 , the prediction equation of AUC could be suggested as shown in Fig. 1.

Compared to previous studies integrating TAM to explain AUC, the findings of this study strongly suggest that this model has the ability to predict and explain AUC among teachers. The adjusted R-square in this study was $54.5 \%$; in the studies of $\mathrm{Hu}$ et al. ${ }^{[4]}$, Mathieson ${ }^{[38]}$, Chau and $\mathrm{Hu}^{[39]}$, Taylor and $\mathrm{Todd}^{[40]}$, it was $72,43.8,42$ and $60 \%$, respectively. Therefore, the model of this study depicts the potential in the explanatory power, with only some minor increase in model complexity. 
The two most important predictors of AUC among MSE secondary school teachers' in this study are perceived ease of use and perceived usefulness. This is in line with what had been stated by Davis ${ }^{[21]}$ and $\mathrm{Hu}$ et $a l .{ }^{[4]}$, that is, perceived ease of use and perceived usefulness are important perceptions that determine information technology adoption and usage. As being added by Clark $^{[41]}$, teachers believe perceived ease of use and perceived usefulness are an integral part of the process of using computers because teachers believe computer technology should be easy to use, its user interface should be less sophisticated and they would feel more confident in their ability to use computer technology if they perceive it as useful.

It is natural that when an idea is perceived to make things easier, it would be readily accepted. So it is with computers. When MSE teachers perceive the usage of computer to ease their burden in many ways, it is not surprising that they would chose to use it extensively. In addition, when MSE teachers find the use of computers to ease the burden in many ways they will automatically accept the computer to be of much use. They do not hesitate to readily resort the computer for their many needs such as in the preparation of classroom materials, setting of examination papers and other student/teacher related tasks.

Job relevance is also an important predictor in determining the AUC among MSE secondary school teachers as had been identified in this study. Similar results were obtained in the studies carried out by Becker and Riel ${ }^{[23]}$ ), Delcourt and Kinzie ${ }^{[42]}$ and Keller $^{[24]}$. Subsequent usage of computers that are seen as relevant to the job increases in consequences as opposed to teachers who do not find these tools to be job relevant. The study shows that the MSE teachers would seek to use computer technology if they find computers to be relevant to their profession and lessen their impediment with the countless jobs that they have in hand on top of achieving targets set by their school administrator.

Computer compatibility is commonly known as the knowledge of computer characteristics, capabilities and applications, as well as user's ability to implement this knowledge productively. The study identified that computer compatibility is one of the predictors to explain AUC among MSE secondary school teachers as had been found in previous studies ${ }^{[4,28,29]}$. MSE secondary school teachers need to be compatible with the hardware and software found in computers, for this is the channel through which they get into the world of computer usage. The final predictor of AUC among MSE secondary school teachers in this study is their attitude towards computer usage.
The study implies MSE teachers need to have the right attitude for it has a great influence on the way they utilize the computers. This is in line with what had been identified in a number of studies that indicate attitude has strong implications on $\mathrm{AUC}^{[19]}$. Teachers must possess a positive attitude towards computer technology so that they will exhibit greater usage of computer. Hence with, MSE teachers need to have the right attitude so that more usage of the computer technology could be implemented in schools to ensure the success of the IT programs and eventually the achievement of Vision 2020.

In line with the advocating of the necessity to use computers in teaching, MSE secondary school teachers are left with no choice but to resort to use computers to impart knowledge. Their belief of the ability of using a computer and the support from peers and administrator has no room to influence the teachers' AUC for it is an accepted fact that all MSE teachers must have the necessary knowledge and skills to be computer literate. Hence computer self-efficacy and subjective norm does not have a significant influence on AUC.

\section{CONCLUSION}

The findings of this study imply that MSE secondary school teachers are more willing to use the computer if they perceive it to be easy to use. This is an important factor that needs to be taken into serious consideration. When something is perceived to be easeof-use, then it is of certain that it would be used successfully. It becomes a surety that MSE secondary school teachers would lucratively use that computer in their teaching and learning if they perceive IT to have a high level of ease-of-use. The AUC will become an authenticity once this implication becomes veracity. Secondly, the study implies that MSE secondary school teachers must perceive the computer to be useful in their teaching. MSE secondary school teachers want to be seen as up-to-date with their teaching methodology.

The traditional chalk and talk teaching is but antiquated. Nothing that is of a considerable perceive of its usefulness will be utilized to its full capacity. The study suggest that when MSE secondary school teachers begin to perceive the usefulness of the IT they begin to accept and use it as the best mode of imparting knowledge to the students without much ado. Thus it is of utmost importance that MSE secondary school teacher know of the usefulness of the computer in order to indulge in the AUC. The study also revealed that the AUC is influenced by the degree of its relevance to the associated job. As teachers, their primary concern is but of course to teach. 
The job of a teacher, which is supposed to teach as the post suggests, was never confined to mere classroom teaching. Along with teaching, comes an endless list of other job related commitments that are of equal importance as to teach. Such commitments would include; the preparation of examination questions and its mark schemes, the keying in of students' personal data, their achievements, marks and results, preparation of minutes, reports, worksheets and testimonials. Therefore, teachers would opt into AUC only when they consider that the computer could ease their burden off the countless jobs that they have in hand with numerous deadlines to meet. When the use of computer is reckoned to be relevant to their job by the MSE secondary school teacher plus if it is found to lessen their impediment thus making it easy to resolve their duty, AUC become an actuality.

Further implications that can be drawn from the study are that the computer should be compatible. The advancement of computer technology has brought great innovation and thus school teachers need to be compatible with computers so that they would utilize them. Computer technology must be flexible in programming, adaptable to the learning environment and user-friendly. Without this, then it calls for adequate resources as without them it might cause many frustrations. For example, a teacher might face an agonizing situation of crashing a disk and losing data. If he or she is not compatible with computer, then having technical support personnel onsite is essential for helping curb the pain. This can help in retrieving lost data or may be able to reduce down time and more importantly to build confidence among school teachers. Therein, the AUC is in fact influenced by the compatibility of the computer itself.

It is also an undeniable fact the AUC has its attributes from the attitude of its user. The above finding of this study showed that MSE secondary school teachers' behavioral factors are important with the usage of computers. If computer technology is to be used extensively in schools, it is pertinent to develop the right kind of attitude that would foster the use of technology and norms of practice that will facilitate the use of technology among secondary school teachers.

To certain extent the existing mind-sets of most secondary school teachers have to be revamped to accommodate a paradigm shift towards accepting instead of fearing the use of computer in schools. It thus makes sense for policy-makers who intend to transform schools via technology investment not to be too cautious and skeptical about the age factor but rather focus on the attitude of the teachers concern. There is a need to create a collegial atmosphere between all teachers especially in the conduct of computer training programs so that sharing of ideas and peer coaching could be implemented regardless of age and teaching experience. As teachers, both senior and junior ones, become familiar with the applications and begin to develop confidence, they can mentor other teachers in their schools and this would hopefully increase the AUC among teaches.

The realization of the importance and the urgency of the need to be able to handle a PC with no phobia has to be imprinted into the minds and souls of MSE secondary school teachers so that their attitude towards the acceptance of this invaluable modern gadget of knowledge could be fully exploited for the betterment of the nation as a whole. In line with this, to enhance greater AUC among teachers, they need to be given the autonomy and high level of control in selecting materials and skills that need to be mastered through computer technology. Besides, they should also experiment with software and technology so that they could find computer technology as something that is useful to them. Once computer technology becomes a seamless environment and then teachers will adapt and see it as another tool that is important in their lives.

\section{RECOMMENDATIONS FOR FUTURE RESEARCH}

The following recommendations for future research are based mainly on the limitations of the study and extended beyond the scope of the study and they are as follows:

- Survey questions were used to gain information from the respondents. It is recognized that the survey questions themselves may be problematic, as teachers might not give honest answers and thus it is recommended that future research should include action research and other techniques of data collection such as interviews, direct observations, experiments and also other standardized scales and inventories that measure AUC among school teachers.

- The findings of this study were limited to the secondary school teachers in the district of Petaling which is in Selangor, Malaysia and many of these teachers were from urban schools that have had wider access to information and communication technology. Thus, there is a possibility that the outcome of this study could not be generalized to the entire secondary school teachers in Malaysia. Future studies could be carried out among teachers in rural schools and also teachers that teach in 
interior parts of schools in East Malaysia and east coast of Peninsular Malaysia. Hence, the results could provide a more complete scenario and a better generalization on the AUC among MSE teachers in Malaysia. This input eventually will be important for policy makers to implement information technology programs across the many schools in Malaysia.

- There are so many constructs that explain the phenomenon of AUC and due to the limitation of resources and based on previous studies and theories support, only seven technology acceptance constructs and five socio-demographic factors formed the framework of the study. It is hoped that future research can pay attention to wider scope of constructs pertaining to AUC and these include psychological attachment, computer coping strategies, technology proficiency, type of school and financial incentives.

- This study integrated the technology acceptance model in measuring the AUC. More research should be carried out by extending the technology acceptance model, while retaining its parsimony and focus in the context of AUC among school teachers. In relation to this, future data analysis should be carried out in a more rigorous way testing to identify causal relationships among constructs and to determine the strength of these constructs that contribute to the path analysis and the final behavior of AUC.

- Future studies could also be implemented by testing the technology acceptance model longitudinally using responses from school teachers that have attended an intensive training program on a particular program or software. By doing so, it will help to determine key acceptance determinants on usage of computer besides gaining information on plausible changes in acceptance drivers over the course of the training that include the influence patterns and magnitudes. The data obtained is most relevant to organize future meaningful computer training programs for school teachers.

\section{REFERENCES}

1. Jung, I., 2001. Singapore's approach to preparing new teachers to use technology in the classroom. Jurong: SUNY Press.

2. Government of Malaysia, 2001. Eight Malaysia Plan. Economic Planning Unit, Prime Minister's Department, Putrajaya.
3. Berita Harian, 2004. Sektor pendidikan dapat peruntukan RM21.5b. September 11, pp: 5.

4. Hu, P.J., T.H.K. Clark and W.W. Ma, 2003. Examining technology acceptance by school teachers: A longitudinal study. Inform. and Manag., 41: 227-241.

5. Chong, C.K., H. Sharaf and D. Jacob, 2005. A study on the use of ICT in mathematics teaching. Malaysian Online J. Instructional Technol., 2 (3): 43-51.

6. MHS Resources, 2005. Preventive maintenance report. Kuala Lumpur: MHS Resources Sdn. Bhd.

7. Yuen, H.K. and W.K. Ma, 2002. Gender differences in teacher computer acceptance. J. Technol. and Teacher Education, 10 (3): 365-382.

8. Wong, S.L., A.B. Kamariah, H. Ramlah and A.T. Rohani, 2002. Malaysian in-service teachers: An assessment of their IT preparedness. In Kinshuk, L.R., K. Akohori, R. Kemp, T. Okamoto, L. Henderson and C.H. Lee (Edn.). Proceedings in the International Conference on Computers in education (ICCE), Auckland: University of Massey.

9. Houtz, S. and P. Gupta, 2001. Gender roles, computer attitudes and dyadic computer interaction performance among teacher educators. J. Org. Behav., 20 (3): 1-9.

10. Lee, V.E., 1997. Effects of high school restructuring and size on early gains in achievement and engagement. Sociology of Education, 68: 241-270.

11. Gan, S.L., 2001. IT and education in Malaysia: Problems, issues and challenges. Selangor: Pearson Education Malaysia.

12. Smith, S., 2001. Relationships to computer attitudes to gender, age, grade level and teacher influence. Education, 106: 338-344.

13. Sia, P.W., 2000. Computer anxiety and computer literacy among urban secondary school teachers in Miri. Unpublished master's thesis. Kota Samarahan: University Malaysia of Sarawak.

14. Angers, J. and K. Machtmes, 2005. An ethnographic-case study of beliefs, context factors and practices of teachers integrating technology. The Qualitative Report, 10 (4): 771-794.

15. Norhayati Abd. Mukti., 2000. Computer technology in Malaysia: Teachers' background characteristics, attitudes and concerns. [Online]. The Electronic Journal on Information Systems in Developing Countries. Available: <http: //www. ejisdc.org $>$.

16. Koh, C.K., 1998. Computer anxiety and attitude towards computer of rural secondary school teachers. Unpublished master's thesis. Kota Samarahan: University Malaysia of Sarawak. 
17. Downing, D.C. and P.A. Rath, 2003. Mentoring overcoming barriers to technology integration. $\mathrm{J}$. Comput. Teacher Education, 32 (1): 54-72.

18. Heinssen, R., D. Glass and J. Knight, 2001. Classroom dynamics in a technology-rich learning environment. J. Comput. Education, 37 (3): 285-311.

19. Yildirim, S., 2000. Effects of an educational computing course on preservice and inservice teachers: A discussion and analysis of attitudes and use. J. Res. Comput. Education, 32 (4): 479-495.

20. Venkatesh, V. and M.G. Morris, 2000. Why do not men ever stop to ask for directions? Gender, social influence and their role in technology acceptance and usage behavior. MIS Q., 24 (1): 115-139.

21. Davis, F.D., 1989. Perceived usefulness, perceived ease of use and user acceptance of information technology. MIS Q., 13 (3): 318-339.

22. Agarwal, R. J. and Prasad, 1999. Are individual differences germane to the acceptance of new information technologies? Decision Sci., 30 (2): 361-391.

23. Becker, H.J. and M.M. Riel, 2002. [Online]. Teacher professional engagement and constructivist-compatible computer use. Centre for Research on Information Technology and Organizations, University of California, Irvine. Available: <http: //www. crito.uci. edu/ tic/ findings.html $>$.

24. Keller, J.M., 2000. Motivational design of instruction. In Reigeluth, C.M. (Edn.), Instructional-design theories and models: An overview of their current status. Hillsdale, New Jersey: Lawrence Erlbaum Associates.

25. Hoffman, B., 2001. Integrating technology into schools. Education Digest, 62 (5): 51-55.

26. Stefl-Mabry, J., 1999. Professional staff development: lessons learned from current usability studies. J. Inform. Technol. Impact, 1 (2): 81-104.

27. Taylor, S., 1996. Understanding information technology usage: A test of competing models. Inform. Syst. Res., 6 (2): 144-176.

28. Morton, A., 2002. Factors affecting integration of computers in western Sydney secondary schools. In Hedberg, J.G., J.R. Steele and S. McNamara (Edn.), Learning technologies: Prospects and pathways. Selected papers from EdTech 2002 biennial conference of the Australian Society for Educational Technology. Canberra, Australia: AJET Publications. (ERIC No. ED 396 737), pp: 107-114.
29. Dusick, D.M., 1998. What social cognitive factors influence faculty members' use of computers for teaching? A literature review. J. Res. Comput. Education, 31 (2): 123-140.

30. Shih, H.P., 2004. Extended technology acceptance model of internet utilization behavior. Inform. and Manag., 41: 719-729.

31. Kellenberger, D.W. and S. Hendricks, 2000. Predicting teachers' computer use for own needs, teaching and student learning. J. Educational Comput. Res., 16 (1): 53-64.

32. Luarn, P. and H. Lin, 2004. Toward an understanding of the behavioral intention to use mobile banking. Comput. Human Behav., 30: 1-19.

33. Malhotra, Y. and D.F. Galletta, 1999. Extending the technology acceptance model to account for social influence: theoretical bases and empirical validation. Proceedings of the 32nd Hawaii International Conference on System Sciences.

34. Venkatesh, V. and F.D. Davis, 1996. A theoretical extension of the technology acceptance model: four longitudinal field studies. Manag. Sci., 46 (2): 186-204.

35. Nunnally, J., 1978. Psychometric theory. New York: McGraw-Hill.

36. Yamane, T., 1967. Elementary sampling theory. Englewood Cliffs, N.J.: Prentice Hall, Inc.

37. SPSS Base 9.0 Applications Guide, 1999. Chicago, Illinois: SPSS Inc.

38. Mathieson, K., 2001. Predicting user intentions: comparing the technology acceptance model with the theory of planned behavior. Inform. Syst. Res., 2 (3): 73-191.

39. Chau, P.Y.K. and P.J. Hu, 2002. Information technology acceptance by individual professionals: A model comparison approach. Decision Sci., 32 (4): 699-719.

40. Taylor, S. and P. Todd, 1995. Assessing IT usage: The role of prior experience. MIS Q., 19 (4): $561-570$.

41. Clark, K., 2000. Urban Middle School Teachers' Use of Instructional Technology. Res. Comput. Education, 33: 178-196.

42. Delcourt, M.A. and M.B. Kinzie, 2002. Computer technologies in teacher education: The measurement of attitudes and self-efficacy. J. Res. and Dev. Education, 27 (1): 35-41. 